\title{
OS DIREITOS HUMANOS COMO NORMAS IMPERATIVAS DE DIREITO INTERNACIONAL E A CORTE EUROPÉIA DE DIREITOS HUMANOS
}

\author{
Douglas Alexander Cordeiro* \\ Natália Villas Bôas Zanelatto**
}

\begin{abstract}
RESUMO
Os direitos humanos assumem, principalmente após a segunda guerra mundial, relevância supranacional ao representarem valores comuns à comunidade internacional e consolidam-se, assim, como normas que devem ser observadas e respeitadas por todos os sujeitos de Direito Internacional. Tal idéia deixa o campo das discussões doutrinárias e passa a integrar decisões proferidas por Tribunais Internacionais, como a Corte Européia de Direitos Humanos.
\end{abstract}

Palavras-chave: Direitos Humanos, jus cogens, normas imperativas de direito internacional, Corte Européia de Direitos Humanos.

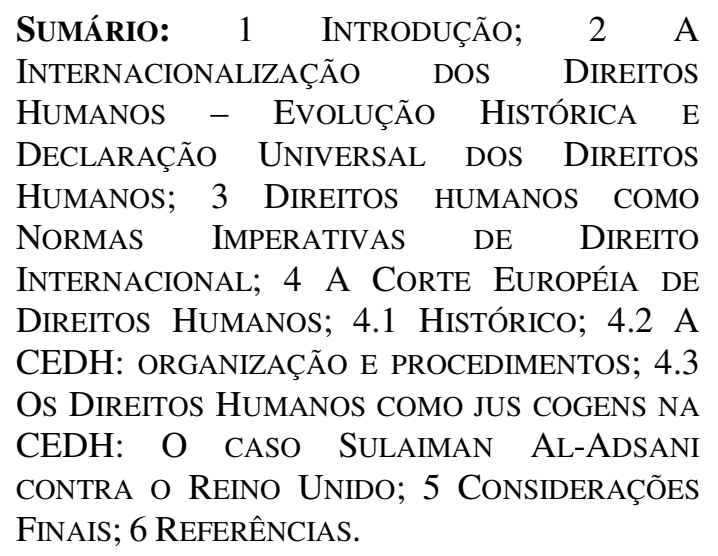

* Graduando em Direito pela Universidade Federal do Paraná, pesquisador do Núcleo de Pesquisa em Direito Público do Mercosul e membro do Núcleo de Estudos em Direito Internacional da UFPR. Email: douglascordeiro@yahoo.com.br

** Graduanda em Direito pela Universidade Federal do Paraná, participante do Núcleo de Estudos em Direito Internacional e do Núcleo de Estudos de Direito Civil da UFPR - Projeto "Virada de Copérnico". Email: nathzane@ hotmail.com 


\section{OS DIREITOS HUMANOS COMO NORMAS IMPERATIVAS DE DIREITO INTERNACIONAL E A CORTE Européia de Direitos HuMANOS}

\section{INTRODUÇÃO}

O desenvolvimento das relações entre Estados gerou a necessidade de se buscar meios para estabelecer quais seriam os valores fundamentais da comunidade internacional, que deveriam ser respeitadas por todos, independentemente de leis internas ou tratados internacionais.

Neste sentido a Comissão de Direito Internacional da ONU direcionou os seus estudos, culminando na previsão, constante da Convenção de Viena sobre o Direito dos Tratados, de 23 de maio de 1969, das normas imperativas de direito internacional geral (jus cogens) nos artigos, 44, 53, 64, 66 e 71.

Tais dispositivos conceituam as normas imperativas de direito internacional geral como aquelas que devem ser aceitas e reconhecidas pela comunidade internacional dos Estados em seu conjunto. Desta maneira, não são passíveis de derrogação e somente podem ser modificadas por norma de direito internacional geral da mesma natureza.

O diploma determina ainda a nulidade e conseqüente extinção de tratado em conflito com norma imperativa de direito internacional superveniente, ou seja, a Convenção concedeu à norma imperativa o poder de anular e extinguir a parte do tratado que com ela for incompatível.

Com efeito, a Comissão de Viena sobre o Direito dos Tratados foi pioneira no tratamento de jus cogens, fato que transformou a Convenção dela resultante no marco conceitual da matéria. Entretanto, deve-se atentar para a sua omissão quanto aos limites do conteúdo das normas imperativas, resultando na indeterminação sobre quais seriam os interesses elementares da comunidade internacional e, consequientemente, merecedores do status de jus cogens.

Para suprir tal lacuna, porém, nos são disponíveis as orientações fornecidas pela própria Comissão, pela doutrina e pela jurisprudência. Pretende-se, aqui, analisar a evolução histórica dos Direitos Humanos no âmbito internacional e, especialmente, o modo como este tema é tratado pela Corte Européia de Direitos Humanos, instituição 
criada no âmbito da Comunidade Européia com o objetivo de assegurar aos seus membros o respeito às disposições da Convenção para a Proteção dos Direitos do Homem e das Liberdades Fundamentais.

\section{A INTERNACIONALIZAÇÃO DOS DIREITOS HUMANOS - EVOLUÇÃO HISTÓRICA E DECLARAÇÃO UNIVERSAL DOS DIREITOS HUMANOS}

Não obstante a polêmica hodierna a respeito da origem e a natureza dos direitos humanos é possível afirmar que eles se materializam graças à intervenção humana e resultam de um processo histórico de conquista de direitos. Assim, de acordo com Norberto Bobbio, os direitos humanos nascem como direitos naturais universais, desenvolvem-se como direitos positivos particulares no momento em que as Constituições os incorporam, e encontram a sua realização plena como direitos positivos universais. ${ }^{1}$

Nesta linha de proteção e promoção dos direitos humanos foram criados, como marcos pioneiros do processo de internacionalização dos direitos humanos, o Direito Internacional Humanitário, previsto nas quatro Convenções de Genebra de 1949, a Liga das Nações e a Organização Internacional do Trabalho, expedientes que contribuíram em grande monta para a criação de um Direito Internacional que transcende os limites do Estado e volta-se à salvaguarda dos direitos humanos. Isso porque apenas após a constituição destes órgãos internacionais rompe-se com a noção de soberania nacional absoluta em prol da proteção dos direitos humanos e surge, então, a idéia de que o indivíduo é também sujeito de direito internacional, resultando no reconhecimento gradativo da sua capacidade processual internacional.

Em seguida observou-se a verdadeira consolidação do Direito Internacional dos Direitos Humanos, ocorrida em meados do século XX, em razão da Segunda

\footnotetext{
${ }^{1}$ BOBBIO, Norberto. A era dos direitos, p. 30.
} 


\section{OS DiREITOS HumANOS COMO NORMAS IMPERATIVAS DE DIREITO INTERNACIONAL E A CORTE EUROPÉIA DE DiREITOS HuMANOS}

Guerra Mundial. O totalitarismo nela presente negou os valores inerentes à pessoa humana como fonte do Direito, o que representou a necessidade de se reconstruir o conceito de Direitos Humanos, como paradigma ético que possa aproximar o Direito à Moral.

Desta maneira, o processo de internacionalização dos direitos humanos está fortemente relacionado à superação da soberania Estatal, conforme se constatou após o fim da Segunda Guerra, em que a forte reação contra os abusos cometidos engendrou a decadência do Nazismo na Alemanha e colocou o absolutismo da soberania estatal em descrença. Isso ocorreu porque o Tribunal de Nuremberg considerou que a Alemanha violou o direito costumeiro internacional que proíbe crimes contra a humanidade, elaborando a primeira decisão a julgar um Estado responsável no âmbito internacional pelo que ocorreu dentro de seu território com os seus nacionais.

Observando ainda o desenvolvimento histórico da internacionalização dos direitos humanos, verifica-se o surgimento das Nações Unidas e a elaboração da sua Carta, de 1945, a qual transformou a relação entre o Estado e seus nacionais em uma problemática internacional. Ela ressalta, em seu artigo 55, a importância da defesa e respeito aos direitos humanos e às liberdades fundamentais dos indivíduos. Deixa, porém, de definir o conteúdo de tais expressões.

Assim, a fixação efetiva de um código comum e universal dos direitos humanos e a concretização da obrigação legal de promover esses direitos só se deu com a elaboração da Declaração Universal dos Direitos Humanos, de 1948, que definiu o elenco dos direitos humanos e liberdades fundamentais. Ela proporcionou o reconhecimento do indivíduo como membro da sociedade humana, um cidadão do mundo e consagrou o respeito à dignidade humana e os valores básicos universais.

Cumpre ressaltar, ainda, que referido diploma apresenta os direitos humanos como uma unidade interdependente e indivisível, incluindo não somente limitações que impedem a interferência dos governos nos direitos civis e políticos, mas abarcando também obrigações governamentais de promoção do bem-estar econômico e social. Isto posto, afirma-se, atualmente, que a interpretação autorizada do conteúdo dos 
Direitos Humanos é a Declaração Universal de 1948, de modo que os membros das Nações Unidas têm a obrigação de promover o seu respeito e observar seu conteúdo.

\section{DIREITOS HUMANOS COMO NORMAS IMPERATIVAS DE DIREITO INTERNACIONAL}

A defesa da espécie humana e de sua dignidade, juntamente com a proteção do ambiente em que vive, constituem os objetivos essenciais e os valores mais caros à comunidade internacional, motivo pelo qual esta deve unir forças para realizá-los.

Os direitos da pessoa humana, quando analisados sob a ótica das normas imperativas de direito internacional (jus cogens), possibilitam quatro diferentes posições doutrinárias. A primeira delas enquadra todos os direitos humanos na categoria de jus cogens, enquanto a segunda consagra somente alguns direitos previstos em determinados textos internacionais como normas imperativas internacionais. A terceira corrente, por sua vez, entende que jus cogens seriam somente aquelas normas de direitos humanos que devem ser respeitadas mesmo quando a nação está em estado de emergência e, a quarta, interpreta como inadequada a invocação do conceito de jus cogens em matéria de direitos humanos, vez que a noção de normas imperativas pressupõe necessariamente uma hierarquia normativa, o que é refutado pela já comentada indivisibilidade dos direitos humanos.

Sob uma perspectiva diversa, Tatyana Friedrich afirma que a efetiva consolidação dos direitos humanos como jus cogens depende de dois reconhecimentos no cenário internacional, que representariam mudanças estruturais: o indivíduo compreendido como sujeito de direito internacional e capaz, juridicamente, de propor ação relacionada à violação de direito internacional perante as cortes nacionais e internacionais. $^{2}$

${ }^{2}$ FRIEDRICH, Tatyana S. As normas imperativas de direito internacional público jus 


\section{OS Direitos HumanOS COMO NORMAS IMPERATIVAS DE DIREITO INTERNACIONAL E A CORTE EuRopéia de Direitos HuMANOS}

No que concerne à questão da personalidade jurídica internacional do indivíduo, vigora ainda a concepção clássica de que a atuação da pessoa física na sociedade internacional se dá unicamente por meio dos Estados. Não obstante essa visão tradicional, como mencionado no ponto supra, assiste-se ao desenvolvimento da idéia da personalidade jurídica internacional individual, baseada no seguinte fato: os indivíduos possuem direitos e deveres, impostos pelos princípios gerais do direito e do costume internacional, referentes à proteção internacional do ser humano. Assim, tendo em vista tais direitos e deveres, os instrumentos internacionais e regionais de direitos humanos têm se aperfeiçoado muito para abrir espaço à atuação individual.

Pode-se destacar, com relação à legitimidade ativa dos sujeitos, a evolução apresentada pela Corte Européia de Direitos Humanos, que prevê a possibilidade de petição individual. Há, também, casos de cortes locais reconhecendo o direito de ação no descumprimento de normas de direito internacional, inclusive aquelas com caráter de jus cogens. ${ }^{3}$

Há, ainda, outro fator indispensável para o reconhecimento dos direitos humanos como jus cogens, que consiste na impossibilidade de afastamento da violação de direitos humanos em razão de doutrinas, como imunidade de jurisdição, ato de Estado, questão política, dentre outros. Sendo assim, não deve haver a possibilidade de os Estados alegarem o afastamento da violência aos direitos humanos, perante as Cortes, em virtude de tais supostas exceções. O reconhecimento de jus cogens pelo direito moderno exige que as Cortes locais neguem imunidade soberana em casos em que o Estado gera danos a um indivíduo mediante violação de uma norma de jus cogens. $\mathrm{O}$ indeferimento do pedido de imunidade justificar-se-ia, então, pela falta de

cogens. Belo Horizonte: Fórum, 2004, p. 106.

3 Convenção para Proteção dos Direitos do Homem e das Liberdades Fundamentais, artigo 34: "O tribunal pode receber petições de qualquer pessoa singular, organização não governamental ou grupo de particulares que se considere vítima de violação por qualquer Alta Parte Contratante dos direitos reconhecidos na Convenção ou nos seus protocolos. As Altas Partes Contratantes comprometem-se a não criar qualquer entrave ao exercício efetivo deste direito". [online] Disponível na Internet via WWW.URL:< http://www.echr.coe.int/NR/rdonlyres/7510566B-AE54-44B9-A163912EF12B8BA4/0/PortuguesePortugais.pdf > . Última atualização em 02 de novembro de 2007. 
soberania do ato danoso praticado pelo Estado.

Com efeito, Cançado Trindade ilustra a importância da relação jus cogens e direitos humanos, apontando que deve-se desenvolver a doutrina e a jurisprudência acerca das normas imperativas de Direito Internacional e das correspondentes obrigações erga omnes de proteção do ser humano, com todas as conseqüências jurídicas em caso de sua violação. Por meio deste desenvolvimento, segundo o renomado autor, poder-se-á superar os obstáculos e dogmas do passado, criando uma verdadeira ordem pública internacional e, em última análise, uma cultura universal de respeito e observância dos direitos humanos. Somente desta maneira, afirma ele, aproximar-se-á da plenitude da proteção dos direitos inerentes ao ser humano. ${ }^{4}$

\section{A CORTE EUROPÉIA DE DIREITOS HUMANOS}

\subsection{HISTÓRICO}

Em meados do século XX, a Europa encontrava-se em ruínas após duas guerras mundiais e a guerra civil espanhola, as quais deixaram marcas profundas na comunidade internacional. Nesse contexto, em que os direitos humanos encontravamse visivelmente abalados, a instituição da Organização das Nações Unidas (ONU) possibilitou um dos primeiros passos em busca de um mecanismo de proteção jurídica internacional aos Direitos Humanos.

Em 10 de dezembro de 1948, a Assembléia Geral da ONU proclamou a Declaração Universal dos Direitos Humanos, a qual se constituiu em uma das mais importantes bases para os demais ordenamentos jurídicos internacionais destinados à proteção desses direitos, como o Conselho da Europa, instituído em 05 de maio de

\footnotetext{
${ }^{4}$ TRINDADE, Antônio Cançado. El derecho internacional de los derechos humanos em el siglo XXI. Santiago: Jurídica de Chile, 2001, p. 423-424.
} 


\section{OS Direitos HumanOS COMO NORMAS IMPERATIVAS DE DIREITO INTERNACIONAL E A CORTE EuRopéia de Direitos HuMANOS}

1949.

Em 1950 foi aberta à assinatura, no seio do Conselho da Europa, a Convenção para a Proteção dos Direitos do Homem e das Liberdades Fundamentais (Convenção), com a intenção de tomar as primeiras medidas destinadas a assegurar a garantia coletiva de alguns dos direitos previstos na Declaração Universal dos Direitos do Homem de $1948^{5}$. A Convenção, que entrou em vigor em setembro de 1953, dispunha uma série de direitos e liberdades e estabelecia um sistema que objetivava garantir o cumprimento das obrigações assumidas pelos Estados contratantes, por meio de três instituições: a Comissão Européia dos Direitos do Homem (criada em 1954), a Corte Européia de Direitos Humanos (instituído em 1959) e o Comitê de Ministros do Conselho da Europa.

A Corte Européia de Direitos Humanos (CEDH) pode ser definida como um órgão internacional no qual, observadas determinadas circunstâncias, são apresentadas denúncias de violações aos direitos garantidos pela Convenção. Antes da reforma ocorrida em 1994, as queixas podiam ser apresentadas pelos Estados contratantes, ou, no caso dos Estados que reconheciam o direito de recurso individual, por particulares contra um dos Estados contratantes, noticiando a violação de um dos direitos garantidos pela Convenção.

As queixas eram então examinadas pela Comissão Européia de Direitos Humanos (Comissão), que apreciava a admissibilidade das mesmas e então se colocava à disposição das partes, com o objetivo de promover uma conciliação. Em não havendo acordo, era redigido um relatório ao Comitê de Ministros do Conselho da Europa (Comitê), informando os passos e formulando um parecer sobre o mérito da causa.

Caso o Estado requerido houvesse aceitado a jurisdição obrigatória da CEDH, a Comissão e qualquer Estado contratante possuíam um prazo de três meses, contados

5 Convenção Européia para a Proteção dos Direitos do Homem e das Liberdades Fundamentais, preâmbulo. 
a partir do envio do relatório ao Comitê, para enviar o caso à CEDH (os particulares não podiam requerer a intervenção da $\mathrm{CEDH})$, a qual proferia então uma decisão decisiva e vinculativa. Caso a queixa não fosse transmitida à $\mathrm{CEDH}$, competia ao Comitê decidir se houve ou não violação da Convenção e arbitrar, eventualmente, uma reparação razoável à vítima.

A Convenção sofreu, porém, a influência de treze protocolos adicionais. Em suma, os protocolos de número 1, 4, 6, 7, 12 e 13 acrescentaram direitos e liberdades aos já constantes da convenção, enquanto o de número 2 deu à $\mathrm{CEDH}$ a possibilidade de emitir pareceres consultivos e o de numero 9 abriu aos requerentes individuais a possibilidade de transmitir o caso à CEDH. O mais importante deles foi, porém, o protocolo de número 11, o qual entrou em vigor em 01 de novembro de 1998 e acabou por reformar o sistema até então vigente, devido ao significativo aumento do número de casos levados aos órgãos da Convenção. Os demais dizem respeito à organização das instituições criadas pela Convenção e aos respectivos aspectos processuais.

\subsection{A CEDH: ORGANIZAÇÃO E PROCEDIMENTOS}

Com sede em Estrasburgo, a CEDH é um órgão internacional perante o qual são apresentadas denúncias de violação aos direitos garantidos pela Convenção, composta por um número de juizes igual ao de Estados Contratantes ${ }^{6}$. Atualmente conta com um quadro de 47 juizes, sendo que os assentos dos juizes referentes a Montenegro e Irlanda encontram-se vagos. ${ }^{7}$

Os juízes atuam de forma individual e não representam seus Estados, pelo que não há restrições quanto ao número de juizes com uma mesma nacionalidade. São eleitos para um mandato de seis anos, sendo que, na primeira eleição, metade dos

\footnotetext{
${ }^{6}$ Convenção, artigo 20.

${ }^{7}$ Posição em 29/10/2007.
} 


\section{OS DiREITOS HumANOS COMO NORMAS IMPERATIVAS DE DIREITO INTERNACIONAL E A CORTE EUROPÉIA DE DiREITOS HuMANOS}

juízes eleitos tiveram um mandato de apenas três anos, com o intuito de renovar o mandato de ao menos metade dos juizes em um período menor de tempo ${ }^{8}$.

Em regra, qualquer Estado contratante ou mesmo qualquer particular que se considere vítima de uma violação da Convenção, por um dos Estados contratantes, pode dirigir queixa diretamente à CEDH. No artigo 35 da Convenção, porém, existem algumas ressalvas quanto ao direito dos particulares de buscar proteção junto à CEDH, ao estabelecer que "o tribunal só pode ser solicitado a conhecer de um assunto depois de esgotadas todas as vias de recurso internas", após seis meses da última decisão interna definitiva. Não serão, também, aceitas queixas anônimas, idênticas à outras já examinadas pela CEDH ou que se considerarem incompatíveis com o disposto na Convenção e seus protocolos.

O processo que tramitar perante a CEDH privilegiará o amplo contraditório e será público, salvo disposição em contrário, e em constatando-se a lesão reclamada, será a parte lesada reparada razoavelmente (em geral, via indenização em dinheiro).

Da decisão proferida pela secção (a CEDH é dividida em secções compostas por sete juízes), caberá recurso ao Tribunal Pleno (composto por dezessete juízes), sendo a sentença proferida por este tribunal considerada definitiva. Este recurso deverá ser interposto em um prazo de três meses da decisão proferida pela secção, e será ainda analisado pelo "colectivo", órgão composto por cinco juízes do Tribunal Pleno, que analisará relevância da questão, admitindo ou negando seguimento ao recurso, tornando-se, então, definitiva a sentença proferida pela secção.

\subsection{OS DIREITOS HUMANOS COMO JUS COGENS NA CEDH: O CASO SULAIMAN AL-ADSANI CONTRA O REINO UNIDO}

Sulaiman Al-Adsani (reclamante), nascido no Reino Unido em 1961,

\footnotetext{
${ }^{8}$ Convenção, artigo 23, 1.
} 
possuidor também da nacionalidade Kwaitiana, em 1991 mudou-se de Londres para o Kwait para defender este país na Guerra do Golfo. Após a invasão do Kwait pelo Iraque, o reclamante permaneceu no país como membro do movimento de resistência.

Durante o período em que permaneceu no Kwait, o reclamante foi preso e torturado. ${ }^{9}$ Após seu retorno à Inglaterra, o reclamante iniciou a busca pela compensação dos danos físicos e morais que sofreu em razão da tortura, contra aqueles que lhe torturaram e contra o Estado do Iraque.

A Alta Corte Britânica, então, confirmou as decisões anteriores em negar, ao reclamante, o direito de perseguir a compensação pelos danos sofridos contra o Estado do Iraque (permitiu a persecução apenas contra os particulares que participaram dos atos de tortura). A Corte alegou, em suma, que de acordo com o Ato de $1978^{10}$, o Estado do Iraque era imune de jurisdição pelas Cortes do Reino Unido e que, as exceções previstas no Ato de 1978 não seriam aplicáveis ao caso. O reclamante recorreu, ainda, alegando que deveriam ser aplicadas as normas internacionais contra tortura, as quais são tão fundamentais que seriam inclusive jus cogens..$^{11}$, mas seu recurso não foi aceito pela House of Lords.

O caso foi então levado à CEDH, a qual confirmou a decisão da Alta Corte Britânica, alegando que não houve violação dos artigos 3 (proibição da tortura) e 6 (direito a um processo eqüitativo).

A importância desse caso, porém, para os fins desse artigo reside nas alegações do reclamante, de que a proibição da tortura, como jus cogens, deveria

9 "There the three above-mentioned individuals held the applicant's head repeatedly underwater in a swimming pool in which there were dead bodies. The applicant was then dragged into a small room where Sheik Jaber Al-Sabah Al-Saud Al-Sabah set fire to mattresses soaked in petrol, as a result of which the applicant was seriously burnt".

10 Jurisdiction of the English court in respect of foreign States is governed by the State Immunity Act 1978. Section 1(1) provides: 'A State is immune from the jurisdiction of the courts of the United Kingdom.

${ }^{11}$ The argument is ... that international law against torture is so fundamental that it is a jus cogens, or compelling law, which overrides all other principles of international law, including the well-established principles of sovereign immunity. 


\section{OS DiREITOS HumANOS COMO NORMAS IMPERATIVAS DE DIREITO INTERNACIONAL E A CORTE EuRopéia de Direitos HuMANOS}

sobrepor-se ao Ato de 1978 e às alegações de imunidade do Estado do Kwait, bem como nos votos dos juízes Christos Rozakis (Grécia), Ireneu Cabral Barreto (Portugal) e Nina Vajic (Croácia), dentre outros.

Para esses juízes, a aceitação de que a proibição à tortura cristalizou-se como norma imperativa de direito internacional implicaria em sua afirmação como norma hierarquicamente superior às demais normas citadas na decisão, o que acarretaria na declaração de violação do art. $6^{\circ}$ da Convenção pelo Reino Unido.

By accepting that the rule on prohibition of torture is a rule of jus cogens, the majority recognise that it is hierarchically higher than any other rule of international law, be it general or particular, customary or conventional, with the exception, of course, of other jus cogens norms. For the basic characteristic of a jus cogens rule is that, as a source of law in the now vertical international legal system, it overrides any other rule which does not have the same status. In the event of a conflict between a jus cogens rule and any other rule of international law, the former prevails. The consequence of such prevalence is that the conflicting rule is null and void, or, in any event, does not produce legal effects which are in contradiction with the content of the peremptory rule.

Para o Juiz Ferrari Bravo, por exemplo, ao confirmar a imunidade do Estado do Kwait, a CEDH perdeu a grande oportunidade de afirmar o status de jus cogens das regras de proibição à tortura, conforme se constata do trecho abaixo:

What a pity! The Court, whose task in this case was to rule whether there had been a violation of Article $6 \S 1$, had a golden opportunity to issue a clear and forceful condemnation of all acts of torture. To do so, it need only have upheld the thrust of the House of Lords' judgment in Regina v. Bow Street Metropolitan Stipendiary and Others, ex parte Pinochet Ugarte (No. 3) (judgment of 24 March 1999 [2000] Appeal Cases 147), to the effect that the prohibition of torture is now jus cogens, so that torture is a crime under international law. It follows that every State has a duty to contribute to the punishment of torture and cannot hide behind formalist arguments to avoid having to give judgment.

Observa-se, assim, que o jus cogens começa a fazer parte das decisões da CEDH. Com as opiniões acima descritas, dá-se início a uma ampla discussão sobre a proibição da tortura como norma imperativa de direito internacional e sua validade perante normas internas e perante tratados internacionais. 
No caso acima descrito, apesar de o reclamante não ter obtido êxito, a proibição à tortura foi aceita como jus cogens e assim afirmada pelos juízes que participaram do julgamento. Dos juizes que discordaram do relator, acima citados, observa-se que têm clara e fundamentada a opinião de que a proibição à tortura é sim norma imperativa de direito internacional e, portanto, deve prevalecer sobre as demais normas em conflito.

\section{CONSIDERAÇÕES FINAIS}

O jus cogens surgiu como inovação da Convenção de Viena sobre o Direito dos Tratados, de 1969, e vem se desenvolvendo durante as últimas quatro décadas, consubstanciando-se em normas peremptórias que contêm os valores mais elementares da comunidade internacional. A criação de tais normas superou a visão individualista de que os Estados somente estariam vinculados às cláusulas dos tratados que assinassem, bem como proporcionou à comunidade mundial um ordenamento unificador. Sendo assim, vigoram hoje, em âmbito internacional, normas imperativas que perpassam o âmbito restrito das nacionalidades e impõem-se mediante um regramento obrigatório respeitado por todos.

Verifica-se, portanto, que tais normas procuram defender, como valores mais estimáveis, a espécie humana e sua dignidade e, para tanto, abarcam os direitos humanos dentre os princípios e direitos protegidos.

A aplicação do jus cogens, no entanto, não se deu de forma instantânea e, ainda hoje, é tema polêmico e constantemente debatido na comunidade internacional. Não obstante, constata-se que algumas decisões de órgãos internacionais - como a Corte Européia de Direitos Humanos -, aos poucos demonstram que determinados direitos, como a proibição à tortura, vêm sendo qualificados como normas imperativas de direito internacional e, assim, devem se sobrepor às demais normas, sejam elas de direito interno ou mesmo de direito internacional. 


\section{OS DIREITOS HuMANOS COMO NORMAS IMPERATIVAS DE DIREITO INTERNACIONAL E A CORTE EUROPÉIA DE DiREITOS HuMANOS}

\section{REFERÊNCIAS}

BARRAL, Welber. Direito internacional: normas e práticas. Florianópolis: Fundação Boiteux, 2006.

COMPARATO, Fábio Konder. Ética: direito, moral e religião no mundo moderno. São Paulo: Cia. das Letras, 2006.

CONVENÇÃO Européia para a Proteção dos Direitos do Homem e das Liberdades Fundamentais. Disponível em http://www.echr.coe.int. Acesso em 25 out. 2007.

CONVENÇÃO para Proteção dos Direitos do Homem e das Liberdades Fundamentais. Disponível em http://www.echr.coe.int/NR/rdonlyres/7510566B-AE5444B9-A163-912EF12B8BA4/0/PortuguesePortugais.pdf. Acesso em 25 out. 2007.

FERREIRA, Gustavo Assed. Corte Européia de Direitos Humanos. In: BARRAL, Welber (org.). Tribunais internacionais. Mecanismos Contemporâneos de Solução de Controvérsias. Florianópolis: Fundação Boiteux, 2004.

FRIEDRICH, Tatyana S. As normas imperativas de direito internacional público jus cogens. Belo Horizonte: Fórum, 2004.

PIOVESAN, Flávia. Direitos humanos e justiça internacional: um estudo comparativo dos sistemas regionais europeu, interamericano e africano. São Paulo: Saraiva, 2006.

RUIZ MIGUEL, Carlos. La ejecución de sentencias el TEDH. Madrid: Tecnos, 1997.

TRINDADE, Antônio Cançado. El derecho internacional de los derechos humanos em el siglo XXI. Santiago: Jurídica de Chile, 2001. 